\title{
Accident Detection System using Android Application
}

\author{
Patil Ashish N. ${ }^{1}$, Yadav Abhilash ${ }^{2}$ \\ Head and Assistant Professor, Department of Computer Science And Engineering, AGTI'S DACOE, Karad, India ${ }^{1}$ \\ Student, Department of Computer Science And Engineering, AGTI'S DACOE, Karad, India ${ }^{2}$
}

\begin{abstract}
The rapid growth of technology has made our easier this advancement in technology also increased traffic hazarded. Hence ratio of road accident increases. Most of the Time loss of life due to poor emergency facilities. Our research provide a solution for accident detection and preventation of human life safety. The application has been divided into four module based on functionalities. This module is designed to built up and integrated system to cover various aspects of android based Automatic vehicle Accident Detection By Using Android application. The application is designed using location tracking using GPS technology.
\end{abstract}

Keywords: Android Smart Phone, GPS (Global Positioning System), GSM (Global System for Mobile Communication).

\section{INTRODUCTION}

Vehicle is the main mode of any type of transportation. There is a need of proper ride as well as security is the main issue today's life's. There is a no any system which alert when accident was happened.

There is a need to design system that will help to victim who suffering for accident. This system design help to send actual accident location and also send emergency message to people who specified in emergency contact list of victim. It is possible an automatic vehicle accident detection by using GPS and GSM module design. We are concerned with the method to use GPS technology.

Here main advantage our system is that to provide immediate hospital service, police service and immediate location tracking of where accident occurs. Thus the main need of project our system is in police station, Hospital etc. Also the main need of our system is for the human life safety. System is useful in different area such as traffic,

Hospital and Transportation etc. If an accident occur in rural area or populated area, this application is more useful for victims. In world there is increase use of vehicle, such resulting increased traffic as well as rise of road accident. This system provide fast availability of safety.

\section{LITERATURE SURVEY}

The accident detection and alert system provide emergency responders with crucial information at the earliest possible time. Reducing the time between when an accident takes place and when it is detected can reduce mortality rates. The entire works have to be integrated with the automobile to validate its functionality and reliability. Thus this work will reduce the accident death ratio in considerable amount even in rural roads. Then it has a great importance in day to day life of the people in the country like India. This proposed work will provide vital information about the accidents even in unpopulated area.[1]

An automatic accident prevention and reporting system is designed and implemented using wireless technologies like SONAR to prevent accident, GPS modem for finding the location of vehicle in terms of latitude and longitude, as well as GSM for sending message on mobile at the receiver end.[2]

The proposed model for accident detection system can prove to be an important aid in constructing smart transport systems in near future if implemented properly Also the system can be used by the owners of the transport companies etc to monitor the vehicle speed, track its real time location etc using the android app. These features can also help in case of vehicle theft etc.[3]

The paper gives a design which has many benefits like low cost, portability, small size. The system uses the microcontroller in conjunction with vibration and alcohol sensor; GPS and GSM interfacing which reduces the alarm time to a large level and gives the location of accident accurately. It can also overcome the issue of lack of automated system for the detection of the site of accident. The time for detecting the site is reduced and the person can be treated as soon as possible which will save many lives.[4]

\section{GPS TECHNOLOGY}

GPS stand for Global Positioning System is a satellite based navigation system .Now a day this is widely used in android phone. This enables GPS receiver to determine their current location time. 
IARJSET

This helps to track location objects and even individuals.

\section{GSM TECHNOLOGY}

GSM stand for global system for mobile communication is a digital telephony system widely used in Europe and other part of the world .GSM used a variation of time division multiple access and is the most widely used of three digital wireless telephony technology. It is a digital cellular technology used for transmitting mobile voice and data services. GSM is the most widely accepted standard in telecommunications and it is implemented globally.

GSM is a circuit-switched system that divides each 200 $\mathrm{kHz}$ channel into eight $25 \mathrm{kHz}$ time-slots. GSM operates on the mobile communication bands $900 \mathrm{MHz}$ and 1800 $\mathrm{MHz}$ in most parts of the world.

GSM makes use of narrowband Time Division Multiple Access (TDMA) technique for transmitting signals. GSM was developed using digital technology. It has an ability to carry $64 \mathrm{kbps}$ to $120 \mathrm{Mbps}$ of data rates. Presently GSM supports more than one billion mobile subscribers in more than 210 countries throughout the world. GSM provides basic to advanced voice and data services including roaming service. Roaming is the ability to use your GSM phone number in another GSM network.

\section{MICROCONTROLLER}

Atmel AT89S52 microcontroller is used for our control unit and it is a heart of detection system. It receives data from the GPS, processes all data and detects the accident location from processed data. Location of accidents also sends by microcontroller. ATMEL AT89S52 is a high performance low power $8 \mathrm{k}$ bytes microcontroller of insystem programmable flash memory. The device is manufactured using Atmel's high density non-volatile memory technology and is compatible with the industry standard 80C51 instruction set. The on-chip flash allows the program memory to be reprogrammed in system or by a conventional non-volatile memory programmer. AT89S52 is a powerful microcontroller which provides a highly flexible and cost effective solution to many embedded control applications.

\section{PROPOSED METHODOLOGY}

\section{Authentication And UI Module}

These module is used by User interface to access system and also provide functionality.

\section{Accident Detection Module}

It consists of impact sensors, Electronic Control Unit (ECU) . The impact sensor senses all vehicle impacts and sends the appropriate signal to the processor (ECU). The electronic control un impact is sensed as when the rate of deceleration exceeds a certain predetermined threshold. In their quest to develop an intelligent safety system (ISS) for vehicles applications.

\section{Google Map Module}

It displays Google Map and shows u exact location of accident and its details. It gets details from SMS from accident location.

\section{Accident Detection Alert and Location Tracker Module}

It generates alert once Accident SMS arrived at System and Display Google Map window Where it automatically track accident location based on position specified in SMS and Generate some kind of alarm. it (ECU) continuously checks the status of the sensors and determine impact signal that meets a pre-set threshold. It also sends the accident occurrence signal to the communication transceiver component of the GPS device. The impact sensors used in this system are based on accelerometers.

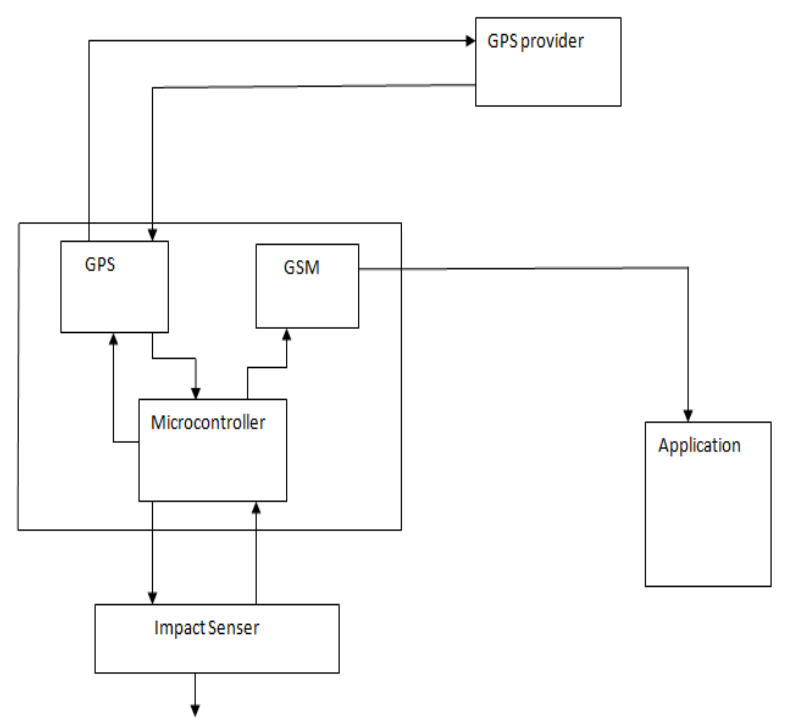

Fig 1 Architecture Diagram

\section{CONCLUSION}

The accident detection and alert system provide emergency responders with crucial information at the earliest possible time. Reducing the time between when an accident takes place and when it is detected can reduce mortality rates. The entire works have to be integrated with the automobile to validate its functionality and reliability. Thus this work will reduce the accident death ratio in considerable amount even in rural roads.

Then it has a great importance in day to day life of the people in the country like India. This proposed work will provide vital information about the accidents even in unpopulated area. So, the pre-configured contacts could be able to serve to the victims with better efficiency and they could plan to have important first aid kits which have to be brought along with them to the accident spot. Thus this work ensures the reduction of death ratio and fatalities in the country like India and also which will have a greater importance in day to day life. 
IARJSET

\section{ACKNOWLEDGEMENT}

It is our privilege to acknowledge with deep sense of gratitude to our project guide and H.O.D Prof. Patil Ashish N. whose supervision, inspiration and valuable discussion has helped us tremendously to complete our project. Their guidance proved to be the most valuable to overcome all the hurdles in the fulfilment of this mega project on "Automatic Vehicle Accident Detection by Using GPS and GSM".

\section{REFERENCES}

1. P.Kaladevi, T.Kokila, S.Narmatha, V.Janani "Accident Detection Using Android Smart Phone" March 2014

2. Rashida Nazir, Ayesha Tariq, Sadia Murawwat*, Sajjad Rabbani "Accident Prevention and Reporting System Using GSM (SIM 900D) and GPS “ 2014

3. Pratiksha R. Shetgaonkar, VijayKumar NaikPawar, Rajesh Gauns "Proposed Model for the Smart Accident Detection System for Smart Vehicles using Arduino board, Smart Sensors, GPS and GSM" July-August 2015

4. Mr.Dinesh Kumar HSDK, Shreya Gupta, Sumeet Kumar, Sonali Srivastava "Accident Detection and Reporting System Using GPS and GSM Module." May 2015 